\title{
The power circuits, the duality of controls and performance appraisal: evidence from a Sri Lankan private university
}

\author{
S. M. Chaturika Seneviratne ${ }^{1 *}$, Ashan Martino ${ }^{2}$ \\ University of Sri Jayewardenepura, Sri Lanka ${ }^{1}$ \\ Holmes Institute, Melbourne, Australia ${ }^{2}$ \\ chaturika@sjp.ac.lk ${ }^{1^{*}}, \underline{\text { LMartino@my.holmes.edu.au }}{ }^{2}$
}

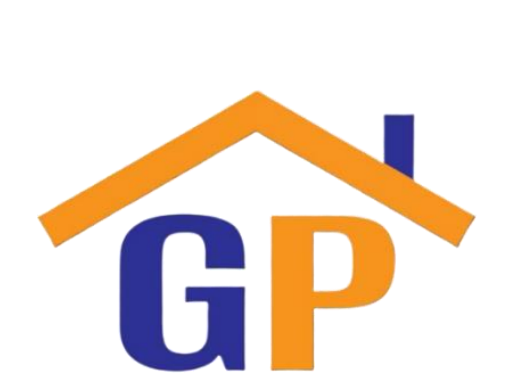

Article History

Received on 21 November 2020

$1^{\text {st }}$ Revision on 30 November 2020

$2^{\text {nd }}$ Revision on 1 January 2021

Accepted on 8 January 2021

\begin{abstract}
Purpose: The study investigates the impacts stemming from the interplay between episodic, dispositional and systemic power circuits through which organisational agents influence or transform the coercive and enabling aspects ingrained in the performance appraisal process in a university setting.
\end{abstract}

Research methodology: The paper uses a single case study method based on a private university. Data was collected using interviews, documentary evidence and observations.

Results: We found that coercive controls become dominance over enabling controls of performance appraisal as an outcome of the ongoing implicit struggle between internal agents who pursue diverse interests and power relations in the private university setting.

Limitations: As the research is directed towards the selection of indepth inquiry of specific setting infused with culture, values, and ideology, it might cause to diminish the researcher's analytical objectivity and independence of the research.

Contribution: The study suggests that the realizing of power remained with the agent's discretion within day-to-day interrelations. Therefore, the agents' power relations are significant in deciding the intensity of dual controls in the performance appraisal practice.

Keywords: Performance appraisal, Power circuits, Enabling controls, Coercive controls, University

How to cite: Seneviratne, S. M., Martino, A. (2021). The power circuits, the duality of controls and performance appraisal: evidence from a Sri Lankan private university. International Journal of Financial, Accounting, and Management, 2(4), 259-273.

\section{Introduction}

The valuable insights are yielded on the concept of balancing between enabling and coercive uses, how it influences unique organisational capabilities and its performance (Henri, 2006; Widener, 2007), and how organisations deal with challenges associated with the duality of controls for the development and management (Frow, Marginson, \& Ogden, 2005; Marginson, 2002; Henttu-Aho, 2016; Beuren \& Santos, 2019: O'Grady, 2019). In a study of Wijethilake, Munir and Appuhami (2018) examines the extent to which enabling and coercive uses of management control systems moderate the relationship between organisational performance and environmental innovation strategy. A similar study on enabling and coercive control examines the incorporation of dual uses in the design characteristics of performance indicators and other control systems and reports how they translate into managers' perception of the control system as being a coercive rather than enabling one (Jordan and Messner, 2012). 
These studies consistently examine critical roles of balancing between dual uses of Management Control Systems (MCS) and dynamic tensions therein but fall short of elaborating the forces affecting the variability of structurally formalised coercive and enabling use or the individual power differences in affecting the central tendency of shifting from coercive to enabling type controls or vice versa in the actual practice of performance appraisal. Such an apparent gap prompted to undertake this study that aimed at analysing the significance of power considering as a multi-layered concept to understand in what ways actual choice, form and intensity of controlling and enabling uses of performance appraisal practices are shaped by asymmetries of power among the agents in diverse hierarchical positions in a research context within the inherent conflict between controlling and enabling formalisations.

Although embedded enabling and coercive uses of budgeting and performance measurement practices are explored in diverse settings (e.g., Chapman \& Kihn, 2009; Jørgensen \& Messner, 2009; Wouters \& Wilderom, 2008), how the "design features" (Adler and Borys ,1996) are really operated as the outcome of an on-going interaction and power relations between different agents is is scarcely explored. Such an apparent gap prompted us to undertake this study that aimed at analysing the significance of power considering as a multi-layered concept in understanding performance appraisal practices of a university and discussing in what ways actual choice and intensity of coercive and enabling uses of performance appraisal practice are shaped by asymmetries of power among the agents in diverse hierarchical positions in a research context within the inherent conflict between controlling and enabling formalisations.This paper reports on a case study of the actual practice of internally enacted management control practice i.e. performance appraisal in a Sri Lankan private university.

In attempting to understand and describe interrelated power circuits operated at diverse levels and their effects on performance appraisal practice, this study employed a qualitative case study approach using a Sri Lankan private university as a case study to provide evidence on a number of issues. The paper illustrates how various agents negotiate their views with both superiors and subordinates and compromise the rules of practice to pursue their interests, and how powerful agents influence the conduct of other officials in operating performance appraisal practices in a field under study. To this end, the study adopted Clegg's circuits of power (1989) to explore power relations, as articulated in Clegg's circuits of power, are invariably embedded in internal practices and constrain or enable practices to different degrees.

The remainder of this paper is organized as follows: the next section introduces the theoretical approach for our study, mainly the discussion of Clegg's circuits of power (1989), and its application in the past research. The third section gives insights about research setting and methodological considerations. Further, empirical findings are presented, illustrating and discussing the power implications on performance appraisal practice. The final section offers a conclusion of the research.

\section{Literature review}

There is a view that coercive use exists in parallel with enabling uses of management control systems, and the importance of balancing these two control processes is also argued (Abernethy \& Brownell, 1999; Ahrens \& Chapman, 2004; Bisbe \& Otley, 2004; Henri, 2006; Marginson, 2002; Mundy, 2010; Tuomela, 2005; Widener, 2007). For Mundy (2010), past studies have not adequately addressed how the balance between coercive and enabling controls can be influenced by power, opportunism and selfinterest. Adler and Borys (1996) asserted that there is limited evidence for understanding the dominance of forces favouring coercive and enabling controls. Building on this, the current paper aims to understand how internal agents are capable of producing effects on management control practice in the field in which they operate, and in the ways in which such micro forces influence determining the practical tendencies of enabling and controlling processes and their relative dominance in an organisational setting.

Whilst the controlling approaches of MCS are concerned with diagnostic uses that exert constraints on options and employees' behaviour, the enabling approach is concerned with interactive uses that encourage employees to search for opportunities to creatively and flexibly solve problems (Ahrens \& 
Chapman, 2004; Simons, 1995). Adler and Borys (1996) discussed whether these two approaches are associated with positive or negative attitudes in employees and found that the adoption of coercive formalisations may assist management to coerce employees' compliance and effort. Generally, MCS are more complex and strongly bound in the concerns of hierarchy and performance measurement (Ahrens \& Chapman, 2004).

Ahrens and Chapman (2004) distinguish between and discuss the enabling and coercive uses of MCS. Adler \& Borys (1996) discuss four design aspects-repair, flexibility, global transparency and internal transparency-which relate to an enabling control approach, as distinguished from a controlling (deskilling) approach. Through a detailed analysis of MCS over a two-year period, Ahrens and Chapman (2004) suggested that the design aspects of enabling controls should be formalised alongside coercive control approaches. Empirically investigating how organisations strikes a balance between controlling and enabling uses and how MCS could be used in a complementary manner to increase organisational capabilities (Mundy, 2010), complementary use of the two forms of MCS is evident. Balancing these competing approaches to create dynamic tension has attracted interest in management control research, as an imbalance may produce unintended consequences for an organisation (Abernethy \& Brownell, 1999; Bisbe \& Otley, 2004; Henri, 2006; Marginson, 2002; Mundy, 2010; Tuomela, 2005; Widener, 2007).

Although enabling and coercive aspects of MCS have been extensively discussed, the forces favouring the enabling or coercive control approach, resulting in one dominating, are scarcely evident in the research (Adler \& Borys, 1996). Therefore, irrespective of the formal design of the MCS, one can argue that the actual operation of enabling and coercive controls is decided by micro forces stemming from the organisational agents, including power, opportunism, self-interest, strategic actions and completing interests. This paper drawing on evidence from an in-depth case study that the ways in which form and intensity of enabling and coercive controls of performance appraisal practice is influenced by the multivaried power relations possessed by diverse agents in a research field.

\section{Research methodology}

\subsection{Theoretical framing}

As the current research attempts to capture the all-inclusive power effects on performance appraisal practices, the Clegg's circuits of power (1989) are vital here to understand how agents take or lose power, who holds power, how power resides, how power/influence is exercised to influence others' conduct with or without resistance, and how power is used in intense negotiations, to communicate and make decisions in day-to-day interactions of management control practice. According to Clegg (1993), as individuals are 'recruited to views of their interests that align with the discursive field of force' ( $\mathrm{p}$. 28), episodic circuits of power are considered alongside dispositional and facilitative power where appropriate in a given research setting. We draw on Clegg (1989)'s development of a comprehensive framework called 'circuits of power', which captures the complexity of power in organisations (Hutchinson, Vickers, Jackson, \& Wilkes, 2010) by interlinking discussion of the capacities and the exercise of power to influence social or organisational practices (Cavaye \& Christiansen, 1996). In particular, this study considers episodic circuit of power among the Clegg's three circuits of power (1989) to examine agents' capacity to act and its actual exercise, which potentially involves the discretion of agent in deciding how to apply the rules of practice (dispositional power) and facilitate power in a given context (Mutiganda, Hassel, \& Fagerström, 2013). As Clegg (1989) argues, power forms various circuits that shape actions of actors in a particular organisational context, and such multivaried power circuits are used to understand the 'inter-related structure of power held by a given number of actors or organizations' (Mutiganda et al., 2013, p. 379). Clegg (1989) identified that power circuits are useful in understanding that power operates in diverse levels, including in visible, invisible, and tenuous manners, however, all three power circuits interact, and it is at the obligatory passage point where, some agents take power, while others lose it (Clegg, 1989).

The episodic circuit represents 'irregular micro-level agential relations' of the ways that 'individuals address feelings, communicate, and offer support and resistance in day-to-day interrelations' (Simpson, 
Clegg, \& Freeder, 2013, p. 391). The concept of episodic power has evolved over some time, attracting diverse theoretical insights. In its simplest form, episodic power is defined as ' $\mathrm{A}$ ' exercising power by utilising resources and means to influence ' $\mathrm{B}$ ' to perform tasks, 'B' would not otherwise do (Dahl, 1957). While Silva Backhouse \& (2003) considered power operating in an episodic circuit as 'power over' or 'causal power', Clegg (1989) emphasised that a unique feature of causal power is that it is followed by resistance.

While acknowledging the importance of understanding episodic power, Clegg emphasised the importance of understanding the arena where power evolves. From the individual's point of view, 'the employer/employee relationship is central, as this constitutes the context in which other forms of organized social relations come into consideration' (Clegg, 1989, p. 196). While noting the concerns that episodic power in isolation may omit the entirety of the power depiction, Clegg added further insights reflecting on two other forms of power circuits: the circuit of social integration and circuit of systemic integration.

The notion of 'standing and material conditions' is recognised as a complex environment through which the outcomes of causal power are realised (Clegg, 1989). Thus, the outcomes of the practices of agents are realised subject to certain conditions and obstructions that are a frequent occurrence of the practices of other agents. Seen in such light, agents 1 are involved in 'arenas of struggle', which determine the outcomes of episodic power and also limit potential outcomes. Within the circuit of social integration, it is conceptualised a set of capacities that distinguish the notion of 'having power' from 'exercising power' (Silva \& Backhouse, 2003). Although there may be characteristics or positions that enable agents to exercise power, this does not necessarily imply actual use of power (Silva \& Backhouse, 2003). The focus is on understanding how rules of meaning and membership influence the social relations, which might be associated with accessibility of resources, authority, and legitimacy which makes actual exercise of power (Backhouse, Hsu, \& Silva, 2006). Thus, the circuit of social integration provides necessary conditions for ' $\mathrm{A}$ ' in terms of providing access to resources and legitimacy in exercising power over 'B' (Backhouse et al., 2006). In other words, the stability of causal power is assigned through fixing the rules of meaning and membership in the organisational context. Facilitative power refers to power exercised in a 'facilitative and positive' manner through techniques of domination at the systemic integration level, either to empower or disempower the capacity to exercise episodic power at the agent/agency level. The circuit of systemic integration is conceptualised as 'material conditions of techniques of production and discipline' (Clegg, 1989, p. 224).

Taken as a whole, observations from the previous section provide a glimpse of the application of the power perspective in accounting research either considering power over accounting, or power of accounting in different organisational and institutional settings. However, little attention has been paid to capturing the various power implications for practical accomplishment of day-to-day management controls in the arena of higher education. The Clegg's circuits of power have made important contributions to theorising power phenomena in the field of accounting. Corroborating the assertion that power is a vital dimension of the budgetary process of public institutions (Covaleski \& Dirsmith, 1986), Lapsley, Midwinter, Nambiar and Steccolini (2011) investigated the interplay between the governmental budget-setting process and power in the Scottish Parliament. By drawing on ideas in episodic, dispositional, and facilitative circuits of power, Lapsley et al. (2011) showed Clegg's circuits of power framework was an effective tool to understand the exercise of power over budget approval during the period of a coalition government. Drawing on the three circuits of power, Mutiganda et al. (2013) explored how taken-for-granted ways of thinking and acting are influenced by the institutionalised accounting information system and how policy makers and organisational leadership are hold different levels of bargaining power during a public procurement competitive tendering process. At the organisational level, Davenport and Leitch (2005) used a circuit of power (Clegg,1989)

\footnotetext{
${ }^{1}$ According to Clegg (1989), the term 'agent' refers to a 'locus of decision and action by a human individual, joint stock company, local council or whatever' (Hindess, 1982, p. 501). In this study, 'agent' refers specifically to the decision and action by individuals of a research organisation in the practice of management controls.
}

2021 | International Journal of Financial, Accounting, and Management/ Vol 2 No 4, 259-273 
to illuminate the appropriateness of strategic ambiguity to delegate authority to multiple and diverse external stakeholder groups in a public-sector funding organisation, finding that a circuit of facilitative power explained the way in which authority was delegated to stakeholders.

Although previous reviews extend our understanding of how circuits of power (Clegg, 1989) have been applied to comprehend the complexity of power phenomena from an integrative perspective, use is limited in the field of accounting research in understanding the total picture of power in the practice of management controls in an organisational setting. The unique contribution of this paper is to document how various agents negotiate their views with both superiors and subordinates and compromise the structurally designed dual controls of performance appraisal to pursue their interests, how powerful agents influence the conduct of other officials in operating performance appraisal, how agents' capacity to act is determined by the interactions of all three power circuits (Clegg, 1989), and such capacities either constrain or facilitate human actions in the real world (Arts \& Van Tatenhove, 2004). Nevertheless, within this broader context, power relations, as articulated in Clegg's circuits of power, are invariably embedded in internal practices, and constrain or enable practices to different degrees. Since University Sigma operates under 'market discipline' (Clegg, 1989), the embedded forms of dispositional and facilitative power in the circuits of social and systemic integration, respectively, may also have implications for understanding individual capacity to act in the management control practice of University Sigma, thereby reinforcing the preliminary intentions to 'make profit and produce returns for investors' (Hallsworth, 1996, p.2128). Clegg's circuits of power are specifically considered here to grasp the episodic exercise of power which interacts with dispositional and systemic power circuits that influences, communicates, and meets probable resistance in the practice of performance appraisal at University Sigma (Simpson et al., 2013).

\subsection{Description of the research site: University Sigma}

To execute the research, access was gained to a prominent university (one large private university) in Sri Lanka. The selection of the case university is justifiable as it facilitates exploring the issues of interest for the research objectives, and it is one of the leading higher education institutions in the higher education sector of Sri Lanka. The research setting was selected for several reasons, including accessibility and perceived issues of interest including the moving towards an outcome-oriented culture and striving to achieve the standards of a world-class university and the significant change in ownership of the university. For all these reasons, University Sigma was selected as a research setting for the study. The university was established by a group of private investors nearly three decades ago as a teaching and training institution. As a market leader in the private higher education field, University Sigma has been striving to safeguard its existing market position and to increase market share, by responding to challenges present in the internal and external context. University Sigma diversified into diverse educational areas including locally and internationally, and caters over 15,000 students, who follow one of over 175 educational and training programmes, from one-day courses to six-year doctoral studies. There are 20 departments operating under four faculties, and conducts courses affiliated with several foreign universities, giving opportunities for Sri Lankan students to excel in higher education at an affordable cost. The organisation has been bestowed with the prestigious National Quality Award for excellence in education services and 'world-class' Global Performance Excellence Award for Education Organisations. The board of directors consists of the chairman, deputy chairman, managing director, joint managing director and eight other directorate positions at similar types of posts at the two main shareholding companies of Sigma. The managing director (chief executive director), ${ }^{2}$ appointed by the board of directors, is responsible for managing day-to-day operations of University Sigma, and held accountable to the board for all company operations. Within the organisational hierarchy, the board of governors and the chancellor occupy parallel positions. Other middle and junior staff consist of branch managers, assistant managers and the librarian.

\footnotetext{
${ }^{2}$ The words chairman, managing director, chief executive officer and president are used interchangeably. Within the organisational setting, the managing director is at the top hierarchical position of organisational structure, and is the group managing directorate of the chain of xxxx private companies that holds the second major shareholding of Sigma University.
} 


\subsection{Data Collection and analysis}

To collect the empirical data, one in-depth case study was carried out within a Sri Lankan private university over seven months during 2014 and 2015. Data were collected using semi-structured interviews, archival documents, and observation of meetings and events. To explore the research objective, it was crucial to understand the wider personal involvement of the internal agents in the performance appraisal practice within the field of Sigma. Thus, narratives from the interviewees were focused on facilitating an understanding of the lived experiences of the agents involved in management control practices. A total of 30 semi-structured interviews were conducted with employees at various hierarchical levels within the research organisation and to complete the interview; time varies from 40 minutes to 120 minutes. Data were also generated from observations from the setting where it operates and also being engaged in an ad-hoc non-participant observations, it was likely to conceptualise the researcher as active and reflexive in the process of generating data pertaining to the place where it happens. Interview and non-participant observational data were supplemented by different archival records.

Thematic analysis is commenced as a pre-requisite to making sense, verifications and drawing conclusions from the empirical findings. Once the field work was completed, transcripts of interviews, observational notes, field notes and relevant documentation were carefully dissected, with identification of key themes and any emerging issues on micro-level interactions in performance appraisal practice in terms of their significance to understanding the research object (Creswell, 2012). Thus, by closely reviewing the entire data set several times and carefully reviewing the pre-set and emergent themes, abstract themes were defined. Once themes were identified, templates were prepared for every theme, to tag and place the information from interview transcripts, observational notes, field notes, memos, and archival documents into the identified categories (Cresswell, 2012). Thus, to bring the richness of the phenomena under study (Lukka \& Medell, 2010), the theoretical framework also become an important guide in searching for the patterns among the coded field evidence and thereby the sense making process and drawing conclusions were essentially integrated with the theoretical underpinnings of Bourdieu's theory of social actions.

\section{Results and discussions}

Annual review and assessment of individual performance are important for University Sigma to stay on course to achieve important departmental and university objectives. Hence, individual performance appraisal is considered as a proactive management practice. It works as a tool to evaluate individual performance and to provide appropriate rewards for employees' contributions towards university objectives. In addition, individual-level performance is evaluated to maintain the competitive advantage of the institution and as a means of maintaining ISO quality standards. The interviews data and documentary evidence revealed that while performance appraisal is designed to use as enabling ways in encouraging the individuals' innovative behaviour, learning processes, a controlling process is used to ensure that individual at the different organisational levels behave according to the pre-established performance standards, policies and procedures (Simons, 1995, Tuomela, 2005).

The performance appraisal process is designed to evaluate an employee's performance over a period of one year. At the beginning of the year, job descriptions are revised and communicated to all hierarchical and functional-level employees of the university, enhancing awareness of the specific tasks to be undertaken in a given year. During the performance appraisal period, individual performance is evaluated against the set standards along with the job description to assess the standard of individual performance and to identify any need for future training or any other career improvement needs.

Supported by interviews and archival documents, individual performance appraisal is designed not only to assess organisational agents but also to enable internal agents to discuss any practical problems in relation to daily operations and university standards and to gather suggestions for future improvement opportunities for individuals, divisions and the university (Ahrens \& Chapman, 2004). The employee 
performance appraisal ${ }^{3}$ consists of two parts. In part A, a subordinate staff member is supposed to provide a self-appraisal about his/her performance relative to given standards. Once part A of the appraisal form is completed, it is forwarded to the immediate superior (appraiser) to complete Part B. The superior ${ }^{4}$ is responsible for evaluating the performance of the employee and assigns marks for the criteria according to pre-decided expectation levels in the performance appraisal form. Although the superior is given the authority to conduct the assessment based on his own observations, second-hand ${ }^{5}$ information is also permissible to verify the ratings presented in Part B.

During the performance appraisal session, individual performance is evaluated according to the specified criteria in the appraisal form and then discusses future development opportunities in a way of relating them to attain the organizational aims. In addition to the appraisal, this process is specific as it provides an opportunity to collect the ideas from different level of employees for the development of University. The performance appraisal practice lies with the primary aim of supporting employees to do their work better by providing feedback on their work, identifying problems and revealing the opportunities for the future improvement etc. (Wouters \& Wilderom, 2008). Hence, it basically designed to serve for the enabling processes by identifying any weaknesses or declines in subordinates' performance to search for the future improvement opportunities including training, workshop and any other learning processes which would beneficial for the individual as well as organisation.

In the process of performance appraisal, part B is a confidential document completed by an immediate superior. The practical difficulty of handling the performance appraisal process to comply with the rules is exemplified by divisional-head-six:

Once I complete Form B, I normally show it to a respective subordinate member and discuss how I rated his/her performance, weaknesses and the need for future development possibilities. I do not keep it confidential. I explain to him/her why he/she is evaluated in this manner in front of them.

The contrasting views are revealed on the way in which part B of the performance appraisal form becomes a non-confidential document at the department level while violating the organisational interests. As the 'confidentiality' of Form B is perceived as inappropriate by divisional heads, they follow alternative conduits through an alternative set of rules in the social integration. Moreover, it can be seen as the stimulating the internal transparency rather by making the visible the internal appraisals to the employees. In that manner, the way in which performance appraisal is completed becomes visible for the appraisee by enhancing the internal trenchancy of the performance appraisal practice (Ahrens \& Chapman, 2004).

Through the performance evaluation practice, as it sought to include any weakness of the subordinate staff with the intention of providing appropriate training and learning opportunities which might ultimately increase the organisational capabilities, the enabling process could be stimulated to certain extent (Wouters, 2008; Simons, 1995; Bisbe, 2004). It appears that the underlying intention of this persistent action is to maintain good relationships with subordinates and reduce any negative attitudes towards the divisional head, which might impede the attainment of improvements in the department. Without following mechanistically, the explicit rules of performance appraisal practice, divisional heads tend to act to fulfil one set of agents' desires, while giving the appearance of obeying the rules of practice. In line with documentary evidence, although the enabling controls of performance appraisal are enlisted in the support of ways to open up opportunities for future improvement, divisional agents tend to perceive coercive visions, mostly assuming that deviations from the standard level of

\footnotetext{
${ }^{3}$ According to rules of practice, except for the Managing Director, all employees' performance is evaluated via performance appraisal practice. However, as this tool is mainly used to evaluate and improve employees' performance, it is the responsibility of both the appraisee and the appraiser to respond to each of the questions completely and accurately.

${ }^{4}$ An appraisee is the immediate superior of the appraiser.

5 The information gathered from Customer Satisfaction Questionnaire and peer evaluations are useful to assess and confirm the evaluation given by the immediate superiors.
} 
performance are suspect or a risk (Adler \& Borys, 1996). As a result, to avoid the suspicion of subordinate members, divisional heads are often involved in the appraisal practice, without considering it as a confidential document.

However, as long as divisional members tend to perceive performance appraisal merely as a mechanism to reward the employees, divisional heads (i.e. head of academic departments) are implicitly pressurised to submit the subordinates' evaluation rather by concealing their weaknesses which are supposed to be mitigated for the future improvement purposes. Hence, the evaluations may not reflect the actual performance level of the employees and it might hinder future learning opportunities that would ultimately negatively impact on increasing organisational and individual capabilities. Within the enabling formalization, although the performance appraisal lies with the intention to assess individual performance against the pre-set standards, thereby identifying and providing future appropriate training and learning opportunities for agents, as true level of agent's performance is not depicted, it is doubtful whether such usability approach is facilitated in private university setting (Adler, 1996; Wouters, 2008). Though employees are trusted and encouraged the contribution to their development in line with the usability approach, such enabling controlling approach could be diminished due to two reasons (Ahrens \& Chapman, 2004). On the one hand, Divisional-heads' practices are emanated spontaneously to merely satisfy the bottom level agents rather concealing weaknesses of the bottom level employees which enviably constrain the future development opportunities and the organisational learning (Henri, 2006). On the other hand, as departmental agents tend to perceive the performance appraisal as a primary mechanism to reward them, they however tend to pursue their own desires keeping less attention in bringing different set of information about the organisational priorities and to stimulate new strategies which might increase the university's capabilities (Henri, 2006).

Pertaining to such power resources, Divisional-heads are possessed with the casual power capacities over the other subordinate members of the department. In that sense, they are essentially held with the casual power pre-configured through the standing conditions enforced by the rules of appraisal practice as dispositional power extant in the Sigma University. Beyond that, their actions on appraisal practices are facilitated by the techniques of disciplines by adopting policies of rewards and sanctions for disciplining their members. Although the immediate superiors' episodic power actions are supported by disposition power circuit and facilitated by the material disciplinary techniques, the practical deployment of performance appraisal seems to be varied from one to another (Silva \& Backhouse,

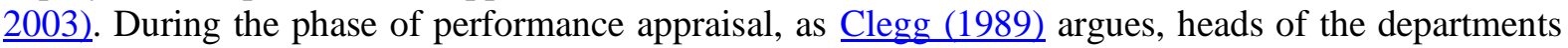
are equipped with sufficient capacities to undertake performance appraisal fairly and secretly being consistent with the university's rules. However, due to the individual centred power capacities, subordinate members are capable in making inherent resistance against the official requirements imposed by the university. However, as tensions due to negative perceptions towards the Divisionalheads in the performance evaluation particularly at the departmental level, Divisional-heads change the practices being deviated from the requirement dictated by the top management. Thus, the bottom level employees attempt to increase their good image which will be positively affect to their salary incremental, bonus, future career improvement and survival in the organisation.

Since divisional-heads are administrative officers who closely work with the academics of their department, they are anxious that if they fail to provide a favourable evaluation of their subordinate employee, it might produce counter-productive results in departmental day-to-day operations. Thus, divisional-heads are not given the freedom to choose their specific action pattern in the evaluation process, as their actions are primarily channelled and prescribed by conflicting desires of top and bottom-level agents. In practice, they are unlikely to highlight the weakness of employees, and the tension encounter in evaluating employee performance.

As departmental-level employees (i.e. lecturers) are the core of the university, divisional-heads strive to work closely with them to ensure their contribution to the success of the department. As per a dean's description, 'We have very little choice. When we want to recruit, we don't have vast choice from which you filter the person who will exactly match to the requirement'. Hence, to avoid any grievances,

2021 | International Journal of Financial, Accounting, and Management/ Vol 2 No 4, 259-273 
divisional-heads may compromise the rules of the performance appraisal strategically, with the aim of ensuring the salary increments and current positions of subordinate members of the academic departments in the field under study. Thus, by overlooking the official rules and procedures enacted by University Sigma, the practical actions of divisional-heads are constituted in a way to ensure the continuous support from bottom-level employees in driving the department towards the assigned targets. Hence, divisional heads implicitly contest the pre-set rules of performance appraisal imposed by dominant agents to define the expected standard and improvement of employee performance in the given field.

While completing Form B, divisional heads have a propensity to promote the interests of the subordinate members of the academic department. Within this backdrop, a divisional head reflected on the difficulty of accomplishing the purposeful and rational objectives of evaluating the performance of subordinate employees via the completion of Form B:

We always let them have a chance to correct their weaknesses rather than writing them on the appraisal form. In reality, as long as the document is not confidential, there is a limit in disclosing the areas to be improved and weaknesses to be addressed. We feel some concern. We are not in a position to point out their weaknesses, because in certain instances, they do their best for the institution.

(Divisional-head-six)

By reinforcing the enabling formalisation, although the performance appraisal is supposed to identify future training and learning opportunities, in the absence of necessary information for future improvement opportunities, the usability approach would be diminished in the private university setting (Adler \& Borys, 1996; Wouters \& Wilderom, 2008). By undermining the visions to bring a different set of information on learning and improvement opportunities and new strategies to increase the university's capabilities in an enabling way, subordinate members of academic departments are more likely to perceive the performance appraisal as a coercive tool to reward/ punish employees (Adler \& Borys, 1996; Henri, 2006). As a result, divisional-heads' practices are emanated merely to satisfy the bottom-level agents, concealing their weaknesses and constraining future development opportunities and organisational learning (Henri, 2006). However, though it was evident that coercive use of assessing individual performance operated alongside enabling controls of performance appraisal (Ahrens \& Chapman, 2004), coercion logics tend to be pursued behind the scenes in the Sigma context.

To achieve the desired outcomes of the performance appraisal practice, agents in different power positions use their discretion in applying rules of practice and choosing between lines of action within the array of practical actions (Law, 1990; Mutiganda et al., 2013). Divisional head is possessed with bureaucratic capital linked to hierarchical level, a wider domain of actions and seniority relative to the subordinate staff of the profit centre (that is academic department). Thus, being the head of a profit centre, he has capacities to control resources and assign responsibilities to subordinate staff and also capable of influencing the conduct of subordinate members of the department. However, there is no guarantee that divisional heads exercise their power in the appraisal practice to align with the institution's interests. Since having power is not always equivalent to exercising power, the divisionalhead's causal power over subordinates is not realised in enacting the rules of appraisal practice (Clegg 1989; Silva \& Backhouse, 2003).

Within the description of the nature of episodic power that individuals use to affect other agents' conduct and beliefs in an organisational setting, Lawrence et al. (2012) asserted that diverse agents are capable of working 'to create, maintain, or disrupt institutions' (p. 107). Primarily, the yearly performance evaluations take place with the intention of improving the quality of service and identifying areas to be improved. However, as the rules of control practice have been bent in order to manage the tension between the desires of top officials and departmental agents, the deployment of divisional-heads' causal power capacity may disrupt the achievement of the objectives of the performance appraisal practice (Lawrence et al., 2012). It could thus be argued that though divisionalheads are reluctant to use causal power in performance appraisals to fulfil the underlying objectives of 
the performance appraisal practice, top management officials, including faculty deans, operate within the episodic circuit of power to maintain the imposed rules of practice in the interests of the university. Given that, while divisional heads echoed the practical difficulty of exercising irregular power to keep Form B confidential, the following controversial ideas were asserted by a top management official: Basically, salary increments are based on the performance appraisal of the employees. One part is self-appraisal. The other section is evaluated by the immediate superior. This is confidential. If there is a problem in an employee's appraisal, we personally address those weaknesses. If the dean or divisional-head says that the respective employee has not performed well, then it will be thoroughly considered. For people not performing well, we try to find a solution for them.

(Vice president)

By validating the fact that the capacity assigned through dispositional power to use discretion in defining the rules of performance appraisal practice may vary based on the power positions agents occupy in an organisation (Arts \& Van Tatenhove, 2004; Mutiganda et al., 2013), the dean, as a member of top management highlighted the importance of tight control of individual performance. By going beyond agents' episodic power capacities, the deploying of power pertinent to the divisional-heads and faculty deans is framed by the existing configuration of dispositional and facilitative circuits of power (e.g., the existing rules of performance appraisal practices and the reward/punishment systems) in the performance appraisal (Ribeiro \& Scapens, 2006).

The empirical evidence of the study reveals that regardless of the given capacity to act (having power), agents situated at diverse power positions may exercise power in different ways (exercising power) with intention of achieving the desired outcome of management control practice. Hence, such difference may due to agent's discretion in applying the rules of practice and the potential to choose between lines of action within the array of practical actions (Law, 1990; Mutiganda et al., 2013). Therefore, being consistent with Mutiganda et al. (2013), how agents take or lose power in the performance appraisal practice depends on the individual discretion, which is influenced by power positions of agents in an organisational hierarchy.

Once the performance appraisal is completed at the departmental level, it is sent to the faculty dean to get his approval. On approval of the faculty dean, it is forwarded to the department of human resources to finalise the employees' ratings according to the given criteria. As the last step, completed forms are sent to the managing director via the vice president, with the intention of obtaining the final recommendation of the yearly salary increment. By considering all the ratings and comments made by the divisional-head and dean, final approval for the salary increment lies with the managing director. Although the salary increment is determined by considering individual performance, there could be instances where the managing director is inclined to base his decision on factors other than the accepted rules of performance appraisal practice. As the rules are 'indexical to the context of interpreters and interpretation' (Clegg, 1989, p. 201; Clegg, 1998), being a dominant agent endowed with a greater scope of permissible actions, the managing director may reinterpret the given rules according to his discretion in facilitating the desire to increase performance to the expected standard in the given context $\underline{\text { (Clegg, 1989). }}$.

In contrast to the rules of performance appraisal, in deciding on the individual increment, the way their increment is determined could be largely opaque to employees, as the managing director retains full control over deciding the percentage of salary increment in the appraisal process. In that sense, since employees may not have a clear understanding about how they are evaluated in approving the salary increment under the causal power capacity of the managing director, coercive logic is evident in the final phase of the performance appraisal practice (Adler \& Borys, 1996). Taken as a whole, through power and influences forces, although visions of enabling controls are superseded by coercive controls of performance appraisal in the actual action, it is reasonable to state that variability of the desired forms of enabling and coercive approaches are evident within the routine practice of performance appraisal in University Sigma. 
By reinforcing the enabling formalisation, although the performance appraisal is supposed to identify future training and learning opportunities, in the absence of necessary information for future improvement opportunities, the usability approach would be diminished in the private university setting (Adler \& Borys, 1996). By undermining the visions to bring a different set of information on learning and improvement opportunities and new strategies to increase the university's capabilities in an enabling way, subordinate members of academic departments are more likely to perceive the performance appraisal as a coercive tool to reward/ punish employees (Adler \& Borys, 1996; Henri, 2006). As a result, divisional-heads' practices are emanated merely to satisfy the bottom-level agents, concealing their weaknesses and constraining future development opportunities and organisational learning (Henri, 2006). However, though it was evident that coercive use of assessing individual performance operated alongside enabling controls of performance appraisal (Ahrens \& Chapman, 2004), coercion logics tend to be pursued behind the scenes in the Sigma context.

Within the enabling formalization, although the performance appraisal lies with the intention to assess individual performance against the pre-set standards, thereby identifying and providing future appropriate training and learning opportunities for agents, as true level of agent's performance is not depicted, it is doubtful whether such usability approach is facilitated in private university setting (Adler \& Borys, 1996; Wouters \& Wilderom, 2008). On the one hand, divisional-heads' practices are emanated spontaneously to merely satisfy the bottom level agents rather concealing weaknesses of the bottom level employees which enviably constrain the future development opportunities and the organisational learning (Henri, 2006). On the other hand, as departmental agents tend to perceive the performance appraisal as a primary mechanism to reward them, they however tend to pursue their own desires keeping less attention in bringing different set of information about the organisational priorities and to stimulate new strategies which might increase the university's capabilities (

\section{Conclusion}

Building on the theoretical and empirical insights of Ahrens and Chapman (2004) and Adler and Borys (1996), the study found that visions of coercive formalisation co-exist with an enabling orientation in performance appraisal practice (Ahrens \& Chapman, 2004). However, in trying to understand and describe performance appraisal practice in its actual actions, the study specifically found that dominance of coercive control over enabling control becomes apparent as an outcome of the on-going implicit struggle between internal agents who pursue diverse interests, strategies of actions and power relations in the field.

In the actual practice, mobilisation of irregular power episodes of the Managing Director over the desires and actions of other agents became most evident where intense decision-making is taking place in performance appraisal practice (Clegg, 1989). In line with Clegg's (1989) argument, it is suggested that 'having power' may be different from the 'exercise of power' in management control practice. Accordingly, although agents are assigned with equal power capacity, the exercise or non-exercise of this power depends on the discretion of an individual during the actual practice of performance appraisal (Hutchinson et al., 2010). Given that, the study may alternatively argue that systemic and dispositional power may not equally define and shape the actions of agents by either enabling or constraining their power relations; instead, it depends on the hierarchical position in which agents are situated in an organisational setting.

Although agents are given equal capacity to exercise the rules of appraisal practice, relying on their own discretion, divisional heads are inclined to bend the rules, whereas faculty deans have a tendency to align with the prescribed procedures (Clegg, 1989; Law, 1990). According to Law's (1990) power, discretion and strategy, irrespective of the assigned power capacity to divisional-heads and faculty deans, the decision to exercise power in operating performance appraisal remains with the discretion of the individual agent. Thus, within the given capacity, the exercise of power to facilitate the intentions of performance appraisal practice is coupled with the agent's discretion, which may highly depend position at which the agent is situated in the power hierarchy of the university. 
The findings of the study show that irrespective of the given capacity to act (having power), agents at different power positions tend to exercise power differently (exercising power), to achieve the desired outcome of management control practice (Hutchinson et al., 2010). This difference may be due to 'discretion' in applying the rules of practice and the potential to choose between lines of action within the array of practical actions (Law, 1990; Mutiganda et al., 2013). Thus, consistent with Mutiganda et al. (2013), it is suggested, although power may be ingrained discursively in an organisational setting, how agents take or lose power in the social practice also depends on the individual discretion, which can be influenced by power positions in an organisational hierarchy. Thus, irrespective of the socially embedded conditions, the exercise of individual power to facilitate or restrain the enabling or coercion controls could be left to the individual's discretion.

Consistent with Hutchinson et al. (2006), the study suggested a 'circuits of power' approach to understanding the 'micro-power at work within the organizations' (p. 123), and how facilitative and dispositional power define, shape and enable agents' behaviour. Thus, Clegg's circuit of power approach provides closer scrutiny of the ways in which internal agents take and lose power and exert irregular micro-power actions ('power over' or causal power), in line with the plethora of discursive power circuits in the day-to-day management control practice. Consistent with Law (1990), the findings suggest that although agents are given the capacity to act, the realising of power also remained with the agent's discretion within day-to-day interrelations.

\section{Limitation and study forward}

According to the ontological and epistemological underpinning of the study, particular theoretical and methodological stances are selected. Perceiving social reality subjectively, the interpretive approach is pursued with the aim of making sense of human action pertinent to management controls and the meanings attached to these within a particular context (Chua, 1986). To achieve that end, as the research is directed towards the selection of in-depth inquiry of specific organisational settings, it inevitably 'infused with culture, values, beliefs, stories, language, perception, cognition, ideology and politics' (Parker, 2012, p. 56). However, alternatively, a positivist researcher may argue that it might cause to diminish the 'researcher independence, accounting neutrality, and analytical objectivity' of the current research (Parker, 2012, p. 56).

Going beyond the current focus of the thesis, there are opportunities to be explored in future research. First, the current study is limited to one case from the Sri Lankan higher education sector. It would be useful to have more cases to explore whether the current findings would be replicated in similar institutions or institutions situated in different contextual settings. In particular, power implication and practice variation of similar types of management controls in comparable institutions could be a potential research avenue for future research. This line of inquiry could be extended to higher education institutions in other countries, and comparative studies of those findings with the findings from the Sri Lankan cases could be a path for future researchers.

Finally, extending the transferability of the theoretical tenets of Clegg's circuits of power, future empirical studies on management control research in the realm of the higher education sector and beyond would be of interest. In particular, institutions and their processes are supposed to be 'powerladen', and power is perceived as a crucial aspect to understand society (Clegg, 2010). Hence, it would be interesting to draw on the theoretical insights of Clegg's three circuits of power to undertake a multilevel research study beyond the purview of the current social setting to capture the 'power over accounting' regarding multi-level power circuits in a specific setting.

\section{References}

Abernethy, M. A., \& Brownell, P. (1999). The role of budgets in organizations facing strategic change: an exploratory study. Accounting, Organizations and Society, 24(3), 189-204. https://doi.org/10.1016/S0361-3682(98)00059-2

Adler, P. S., \& Borys, B. (1996). Two types of bureaucracy: enabling and coercive. Administrative Science Quarterly, 61-89. https://www.jstor.org/stable/2393986 
Arts, B., \& Van Tatenhove, J. (2004). Policy and power: a conceptual framework between the 'old' and 'new' policy idioms. Policy Sciences, 37(3-4), 339-356.

https://link.springer.com/content/pdf/10.1007/s11077-005-0156-9.pdf

Ahrens, T., \& Chapman, C. S. (2004). Accounting for flexibility and efficiency: a field study of management control systems in a restaurant chain*. Contemporary accounting research, 21(2), 271-301. https://onlinelibrary.wiley.com/doi/abs/10.1506/VJR6-RP75-7GUX-XH0X

Backhouse, J., Hsu, C. W., \& Silva, L. (2006). Circuits of power in creating de jure standards: Shaping an international information systems security standard. MIS Quarterly, 30, 413-438. https://www.jstor.org/stable/25148767?seq=1

Bisbe, J., \& Otley, D. (2004). The effects of the interactive use of management control systems on product innovation. Accounting, Organizations and Society, 29(8), 709-737. https://www.sciencedirect.com/science/article/pii/S0361368203000722

Beuren, I.M., \& Santos, V. (2019). Enabling and coercive management control systems and organizational resilience. Revista Contabilidade \& Finanças - USP, 30 (81), 307-323. https://www.scielo.br/scielo.php?pid=S1519-70772019000300307\&script=sci_arttext

Cavaye, A. L., \& Christiansen, J. K. (1996). Understanding IS implementation by estimating power of subunits. European Journal of Information Systems, 5(4), 222-232. https://orsociety.tandfonline.com/doi/abs/10.1057/ejis.1996.28\#.X-v1rS0r1QI

Clegg, S. (1989). Frameworks of power. Thousand Oaks, California: Sage. https://books.google.lk/books?hl=en\&lr=\&id=6Q2e59rjYlAC\&oi=fnd\&pg=PP1\&dq=Clegg,+ S.+(1989).+Frameworks+of +power.+Thousand+Oaks,+California:+Sage\&ots=mWeWvrXGx\&sig=aiuYKgejF9t6_E-OZTDKQND3eg0\&redir_esc=y\#v=onepage\&q\&f=false

Clegg, S. (2010). The state, power, and agency: Missing in action in institutional theory? Journal of Management Inquiry, 19(1), 4-13. https://journals.sagepub.com/doi/abs/10.1177/ 1056492609347562

Chua, W. F. (1986). Radical developments in accounting thought. Accounting Review, 61(4), 601632. https://www.jstor.org/stable/247360?seq=1

Chapman, C.S., \& LA Kihn, L, A., (2009). Information system integration, enabling control and performance. Accounting, organizations and society, (34) 2, 151-169. https://doi.org/10.1016/j.aos.2008.07.003

Covaleski, M. A., \& Dirsmith, M. W. (1986). The budgetary process of power and politics. Accounting, Organizations and Society, 11(3), 193-214. https://www.sciencedirect.com/science/article/pii/0361368286900218

Creswell, J. W. (2012). Qualitative inquiry and research design: Choosing among five approaches. (3rd ecred.). Thousand Oaks, California: Sage publication.

https://books.google.lk/books?hl=en\&lr=\&id=OJYEbDtkxq8C\&oi=fnd\&pg=PP1\&ots=eQ0lb JJogr\&sig=Of9zQS0fNOTfoHdFUTiQnv1enT0\&redir_esc $=\mathrm{y} \# \mathrm{v}=$ onepage\&q \&f $=$ false

Dahl, R. A. (1957). The concept of power. Behavioural Science, 2(3), 201-215. https://onlinelibrary.wiley.com/doi/abs/10.1002/bs.3830020303

Davenport, S., \& Leitch, S. (2005). Circuits of power in practice: Strategic ambiguity as delegation of authority. Organization Studies, 26(11), 1603-1623. https://journals.sagepub.com/doi/abs/10.1177/0170840605054627

Frow, N., Marginson, D., \& Stuart, O. (2005). Encouraging strategic behaviour while maintaining management control: multi-functional project teams, budgets, and the negotiation of shared accountabilities in contemporary enterprises. Management Accounting Research, 16(3): 269292. https://www.sciencedirect.com/science/article/pii/S1044500505000375.

Jørgensen, B., \& Messner, M. (2009). Management control in new product development: the dynamics of managing flexibility and efficiency. Journal of Management Accounting Research, 21 (1): 99-124. https://doi.org/10.2308/jmar.2009.21.1.99

Henri, J.F. (2006). Management control systems and strategy: A resource-based perspective. Accounting, Organizations and Society, 31(6), 529-558. https://www.sciencedirect.com/science/article/pii/ S0361368205000371 
Hutchinson, M., Vickers, M., Jackson, D., \& Wilkes, L. (2006). Workplace bullying in nursing: Towards a more critical organisational perspective. Nursing Inquiry, 13(2), 118-126. https://onlinelibrary.wiley.com/doi/abs/10.1111/j.1440-1800.2006.00314.x

Hutchinson, M., Vickers, M. H., Jackson, D., \& Wilkes, L. (2010). Bullying as circuits of power: An Australian nursing perspective. Administrative Theory \& Praxis, 32(1),25-47. https://www.tandfonline.com/doi/abs/10.2753/ATP1084-1806320102

Jordan, S, \& Messner, M. (2018). Enabling control and the problem of incomplete performance indicators. Accounting, Organisation and Society, 37 (2012) 544-564. https://www.sciencedirect.com/science/article/pii/S0361368212000839

Lawrence, T. B., Malhotra, N., \& Morris, T. (2012). Episodic and systemic power in the transformation of professional service firms. Journal of Management Studies, 49(1), 102-143. https://onlinelibrary.wiley.com/doi/abs/10.1111/j.1467-6486.2011.01031.x

Law, J. (1990). Power, discretion and strategy. The Sociological Review, 38(S1), 165-191. https://journals.sagepub.com/doi/abs/10.1111/j.1467-954X.1990.tb03352.x

Lapsley, I., Midwinter, A., Nambiar, T., \& Steccolini, I. (2011). Government budgeting, power and negotiated order. Management Accounting Research, 22(1), 16-25. https://www.sciencedirect.com/science/article/pii/S1044500510000892

Lukka, K., \& Modell, S. (2010). Validation in interpretive management accounting research. Accounting, Organizations and Society, 35(4), 462-477. https://www.sciencedirect.com/science/article/pii/S0361368209001019

Hallsworth, A. (1996). Buying power-interpreting retail change in a circuits of power framework. Environment and Planning A, 28,2125-2137. https://journals.sagepub.com/doi/abs/10.1068/ a282125

Hindess, B. (1982). Power, interests and the outcomes of struggles. Sociology, 16(4), 498-511.

Henttu-Aho, T. (2016). Enabling characteristics of new budgeting practice and the role of controller. Qualitative Research in Accounting \& Management, 13 (1), 31-56. https://www.emerald.com/insight/content/doi/10.1108/QRAM-09-2014-0058/full/html

Mutiganda, J. C., Hassel, L. G., \& Fagerström, A. (2013). Accounting for competition, 'circuits of power' and negotiated order between not-for-profit and public sector organisations. Financial Accountability \& Management, 29(4), 378-396. https://onlinelibrary.wiley.com/doi/abs/10.1111/faam.12023

Marginson, D. E. (2002). Management control systems and their effects on strategy formation at middle-management levels: Evidence from a UK organization. Strategic Management Journal, 23(11), 1019-1031. https://onlinelibrary.wiley.com/doi/abs/10.1002/smj.271

Mundy, J. (2010). Creating dynamic tensions through a balanced use of management control systems. Accounting, Organizations and Society, 35(5), 499-523. https://www.sciencedirect.com/science/article/pii/S0361368209001020

O'grady, W. (2019). Enabling control in a radically decentralized organization. Qualitative Research in Accounting \& Management, 16(2), 224-251. https://www.emerald.com/insight/content/doi/10.1108/QRAM-07-2017-0065/full/html

Parker, L. D. (2012). Qualitative management accounting research: Assessing deliverables and relevance. Critical Perspectives on Accounting, 23(1), 54-70. https://www.sciencedirect.com/science/article/pii/S1045235411000761

Ribeiro, J. A., \& Scapens, R. W. (2006). Institutional theories in management accounting change: Contributions, issues and paths for development. Qualitative Research in Accounting \& Management, 3(2), 94-111. https://scholar.google.com/scholar?cluster $=5568675158797451010 \& h l=e n \& a s \_s d t=0,5$

Silva, L., \& Backhouse, J. (2003). The circuits-of-power framework for studying power in institutionalization of information systems. Journal of the Association for Information Systems, 4(1), 14. https://aisel.aisnet.org/cgi/viewcontent.cgi?article=1216\&context=jais

Simons, R. (1995). Levers of control: how managers use innovative control systems to drive strategic renewal. Harvard Business Press. https://books.google.com/books?hl=en\&lr=\&id=FWkXQK3nxIC\&oi=fnd\&pg=PR1\&dq=Lev ers+of+ontrol 
Simpson, A., Clegg, S., \& Freeder, D. (2013). Compassion, power and organization. Journal of Political Power, 6(3), 385-

404.https://www.tandfonline.com/doi/abs/10.1080/2158379X.2013.846558

Tuomela, T.-S. (2005). The interplay of different levers of control: a case study of introducing a new performance measurement system. Management Accounting Research, 16(3), 293-320. https://www.sciencedirect.com/science/article/abs/pii/S1044500505000363

Widener, S. K. (2007). An empirical analysis of the levers of control framework. Accounting, Organizations and Society, 32(7), 757-788. https://www.sciencedirect.com/science/article/pii/S0361368207000049

Wouters, M., \& Wilderom, C. (2008). Developing performance-measurement systems as enabling formalization: A longitudinal field study of a logistics department. Accounting, Organizations and Society, 33(4), 488-516. https://www.sciencedirect.com/science/article/pii/S0361368207000438

Wijethilake, C., Munir,R. \& Appuhami, R.(2018). Environmental innovation strategy and organizational performance: enabling and controlling uses of management control systems. Journal of Business Ethics, 151, 1139-1160. https://link.springer.com/article/10.1007/s10551016-3259-7. 